Int. J. Dev. Biol. 52: 791-796 (2008)

doi: $10.1387 / \mathrm{ijdb} .072521 \mathrm{kz}$

\title{
The evolution of sea urchin sperm bindin
}

\author{
KIRK S. ZIGLER* \\ Department of Biology, The University of the South, Sewanee, TN, USA
}

\begin{abstract}
Sea urchins have been model organisms for the study of fertilization for more than a century. Fertilization in sea urchins happens externally, which facilitates the study of sperm-egg attachment and fusion, and means that all of the molecules involved in gamete recognition and fusion are associated with the gametes. Sea urchin sperm bindin was the first "gamete recognition protein" to be isolated and characterized (Vacquier and Moy 1977), and bindin has since been studied by developmental biologists interested in fertilization, by biochemists interested in membrane fusion and by evolutionary biologists interested in reproductive isolation and speciation. Research on bindin was last reviewed thirteen years ago by Vacquier et al. (1995) in an article titled "What have we learned about sea urchin sperm bindin?" in which the authors reviewed the identification, isolation and early molecular examinations of bindin. Research since then has focused on bindin's potential role in fusing egg and sperm membranes, comparisons of bindin between distantly related species, studies within genera linking bindin evolution to reproductive isolation, and studies within species looking at fertilization effects of individual bindin alleles. In addition, the egg receptor for bindin has been cloned and sequenced. I review this recent research here.
\end{abstract}

KEY WORDS: sea urchin, bindin, gamete recognition protein, Echinoidea, fertilization

\section{Overview of early research}

Interested readers should refer to Vacquier et al. (1995) for details and references regarding the early stages of study of bindin. An overview is provided here.

Ultrastructural analyses of sea urchin sperm suggested that the contents of the acrosomal granule coated the acrosomal process after the acrosomal reaction and bound sperm to eggs (Dan 1967; Summers et al., 1975). Vacquier and Moy (1977) isolated the contents of the sea urchin acrosomal granule, which was shown to be a single protein. They named this protein 'bindin' for its role in binding sea urchin sperm to eggs. Agglutination experiments showed that bindin was species-specific in its binding to eggs (Glabe and Lennarz 1979; Glabe and Vacquier, 1977). That is, bindin from one sea urchin species was more effective at binding to eggs of its own species than it was at binding to eggs of another species. The cloning and sequencing of bindin first from Strongylocentrotus purpuratus (Gao et al., 1986) and later from three other sea urchin species ( $\mathcal{S}$. franciscanus, Lytechinus variegatus, and Arbacia punctulata(Minor et al., 1991; Glabe and Clark 1991)) gave insight into the structure and evolution of the molecule.

Bindin is translated as a precursor molecule that contains a prepro- region which is subsequently cleaved to form the mature bindin that is found in sperm (Gao et al., 1986; Fig. 1). Comparisons of bindin between species indicated that mature bindin consists of a 'core' region of 55 amino acids, highly conserved even among different sea urchin orders, with more variable regions flanking the core. Repeats are present in the flanking regions in some species (Fig. 1). Agglutination experiments with modified recombinant bindin and fertilization interference experiments with peptides based on partial bindin sequences provided evidence for a role in species-specificity for the variable flanking regions (Lopez et al., 1993; Minor et al., 1993).

\section{Bindin as a membrane fusogen}

Bindin binds sperm to eggs, and, in agglutination experiments, binds eggs to one another in the absence of sperm. It has been less clear if bindin has a role in sperm-egg membrane fusion, another critical step in fertilization. Early research showing that bindin could induce the fusion of phospholipid vesicles suggested a role for bindin in sperm-egg membrane fusion (Glabe 1985a, b). Subsequent research has focused on an 18 amino acid peptide derived from the conserved core region of bindin (Ulrich et al., 1998). This peptide ('B18', with an amino acid sequence of

*Address correspondence to: Kirk Zigler. 735 University Avenue, Sewanee, TN 37383, USA. Fax: +1-931-598-1145. e-mail: kzigler@sewanee.edu

Published online: 4 July 2008

$0214-6282 / 2008 / \$ 35.00$

(C) UBC Press

Printed in Spain 
LGLLLRHLRHHSNLLANI, Fig. 1) is present and its sequence is conserved in all species from which bindin has been cloned and sequenced (Zigler and Lessios 2003a). The B18 peptide selfassociates and is able to induce the fusion of lipid vesicles (Ulrich et al., 1998). The current 'boomerang' model for the action of the B18 peptide is that it forms a helix-break-helix motif with a hydrophobic $\alpha$-helix at each end (Afonin et al., 2004). The more hydrophobic of these $\alpha$-helices inserts into the lipid bilayer, disrupting the lipid membrane, while the other $\alpha$-helix remains on the surface of the membrane where it replaces water molecules in the lipid headgroups. In combination, these actions favor the aggregation and fusion of lipid membranes (Afonin et al., 2004).

Although experiments with B18 deal with just a portion of the bindin molecule, the fact that the amino acid sequence of the B18 region is perfectly conserved across thirteen genera and more than thirty species of sea urchins supports the idea that it plays a central and conserved role in the function of bindin. Thus, it seems probable that bindin plays two roles in sea urchin fertilization: it functions in sperm-egg attachment and it is involved in the fusion of the gamete membranes.

\section{Taxonomic distribution of bindin}

How widely is bindin distributed taxonomically? Bindin was first cloned and sequenced from species representing two sea urchin orders, the Echinoida and the Arbacioida (Gao et al., 1986; Minor et al., 1991). Bindin has since been cloned and sequenced from representatives of several other distantly related orders of class Echinoidea, including the sand dollars (Clypeasteroida), the heart urchins (Spatangoida), the diadematoids (Diadematoida), and the pencil urchins (Cidaroida) (Zigler and Lessios 2003a). The pencil urchins are the sister group to all other extant echinoids, from whom they diverged approximately 250 mya (Smith et al., 2006). The presence of bindin in the pencil urchins and many other echinoid orders places a minimum bound on its origin: at least 250 mya. Since that time, bindin has been conserved in at least six orders of sea urchins (Zigler and Lessios 2003a).

Bindin is widespread within the echinoids, but is bindin present

1 MGVHQISVIIVIVAFTFTRAVDDFPSRTDVPSDCPEASSGCWCHDSFAQCWRTYDDSHVT

61 SAMGNRITQLELLYQTSEEVVTYIRGMSALRKLRISEDGVSLDCSCDIIYALDDERVTLI 121 DQNELVFGNCREHGFPLDRMTARPF INHCH I LRMQDAETRKRRDADDEDDDVSKRASPRK 181 GDKPAGHKINLKDLDPSSPTKVHHLVSTDDADQLKHHPASDIVNFISRHRRNRRSAATGD 241 EVSDDSERGGRQKR

YGNYPQAMNP PMGGGNYPAPGQAPMGQLAQQGYAAPGMGGPVGGGG

301 AMASPIGGGGAMARPVGFGGAMARPVGGGGAMARPVGGGGAMARPVGGGGAMARPVGGGR

361 AGPPGYGGISQAAGGNDEDYSSSSDEEETTISAKVMMNI $\stackrel{*}{\text { KAVLGATKIDLPVDINDPYDL }}$

421 GLLLRHLRHHSNLLANIGDPEVREQVLSAMQEEEEEEEEEQDAANGVRDNVLSNLNANGP

481 YRAGFGGGGGGMHAGGGGGGGGGRGGMGVVGGRGGGGGMMGFPGMGGQGNAYNPGYRQG

Fig. 1. Deduced amino acid sequence of full-length bindin from Echinometra lucunter (Genbank Accession AAR18072, McCartney and Lessios (2004)). Preprobindin extends from amino acids 1-254, ending with the splice site (in italics). Mature bindin consists of amino acids 255539. The core region is boxed, the fusogenic 'B18' region (Ulrich et al., 1998) is in bold, the repeats $5^{\prime}$ of the core are underlined, and the location of the intron is marked with an '*'. outside this class of animals? Thus far, there is no evidence that it is. Molecules homologous to bindin have not been identified in mechinoid metazoan genomes that have been ding been sequenced (that of Strongylocentrotus purpuratus (Sea Genome Sequencing Consortium 2006)) it remains pos(sea far no evidence to support this possibility. In fact, abindin antibody failed to react with the sperm of three species of sea stars (Moy (1979), and genomic probes using a sea urchin (Minor et al, 1991). An answer to whether bindin is present outside the echinoids awaits either the identification of bindin in -echinoid group, or else a series of convincing negative results in the form of sequenced genomes from other echinoderms.

\section{Bindin evolution across orders}

The six echinoid orders from which bindin is known diverged from one another 200 or more mya (Smith et al., 2006). How has evolved in these independent lineages over this great ? First, we can note three features of the molecule and the splice site between the preprobindin and the mature bindin (Fig. 1). The 55 amino acid core has been remarkably ved, including a stretch of 29 amino acids in the center of and these 29 amino acids. Second, in the three orders from which genomic sequences of bindin are available, an intron is located five amino acids 5' of the the beginning of the core region (Fig. 1). Third, a motif of four basic amino acids is conserved at the presumed splice site between the preprobindin and the mature bindin portion of the molecule (Zigler and Lessios 2003a; Fig. 1). Such motifs mark the cleavage site for proprotein convertases (Seidah and Chretien 1999) and suggest that bindin in all of these orders is processed by cleavage to form mature bindin.

How does bindin differ between species based on these examples from six different orders? Two major differences are evident. First, mature bindin differs greatly in length among these orders, ranging from 193 amino acids in Encope (Mellitella) stokesii (Order Clypeasteroida) to 418 amino acids in Diadema antillarum (Order Diadematoida). A second major difference is that bindins from some orders contain loosely repeated motifs, whereas bindins from other orders do not. These repeats may be located 5' or 3' of the core region, and are typically glycine-rich. Repeats are present in bindin sequences of members of the order Echinoida (e.g. in Echinometra lucunter 5' of the core 
TABLE 1

SUMMARY OF STUDIES EXAMINING BINDIN EVOLUTION WITHIN SEA URCHIN GENERA

\begin{tabular}{|c|c|c|c|c|c|}
\hline Genus & Species examined & Distribution of examined species & Positive selection? & Form of selection & Reference \\
\hline Arbacia & 4 & All allopatric & No & & Metz et al. 1998 \\
\hline Echinometra (Neotropical) & 3 & One allopatric, two sympatric & Yes & along the lineage leading to $E$. lucunter & McCartney and Lessios 2004 \\
\hline Echinometra (Indo-Pacific) & 4 & All sympatric & Yes & between species for region 5 of the core & Metz and Palumbi 1996 \\
\hline Heliocidaris & 2 & All sympatric & Yes & along the lineage leading to $H$. erythrogramma & Zigler et al. 2003 \\
\hline Lytechinus & 6 & Four allopatric, two sympatric & No & & Zigler and Lessios 2004 \\
\hline Strongylocentrotus & 7 & All sympatric & Yes & between species for regions $5^{\prime}$ and $3^{\prime}$ of core & Biermann 1998 \\
\hline Tripneustes & 3 & All allopatric & No & & Zigler and Lessios 2003 \\
\hline
\end{tabular}

GMGGPVGGGG-AMASPIGGGG-AMARPVGFGGAMARPVGGGG-AMARPVGGGG-AMARPVGGGGAMARPVGGGR, Fig. 1) and in Moira atropos, the single representative of the Spatangoida that has been studied, but are not present in bindins of the studied species from the Cidaroida, Diadematoida, Clypeasteroida and Arbacioida (Zigler and Lessios 2003a).

\section{Bindin evolution within genera}

In contrast to the situation when Vacquier et al. (1995) reviewed sea urchin bindin, where the only intrageneric comparison possible was between Strongylocentrotus purpuratus and $\mathcal{S}$. franciscanus, there now exists considerable information about how bindin has evolved within different genera of sea urchins. Studies on six genera of sea urchins have been conducted (Table 1 ), and studies on several more genera are underway. Perhaps the most remarkable recent discovery about bindin has come from these studies: from one genus to another, patterns of bindin evolution differ greatly. Gamete recognition proteins from a wide range of taxa have been shown to evolve rapidly, often under positive selection (reviewed in Swanson and Vacquier 2002). This is the case in the echinoid genera Echinometra, Heliocidaris, and Strongylocentrotus. In each of these genera there is evidence of positive selection for change on bindin (Metz and Palumbi 1996; Biermann 1998; Zigler et al., 2004; Table 1). However, in contrast to results from those genera, there is no evidence for positive selection in the genera Arbacia, Lytechinus, and Tripneustes (Metz et al.1998; Zigler and Lessios 2004; Zigler and Lessios 2003b).

Consistent with its central role in sea urchin fertilization, bindin divergence is correlated with gamete incompatibility; species with bindins that are highly similar are gametically compatible, whereas those with bindins that have diverged from one another are gametically incompatible. In fact, bindin divergence better predicts gamete compatibility between species than the length of time since two species diverged (as estimated from mitochondrial DNA divergence) (Zigler et al., 2005). In some cases patterns of bindin evolution give clear insight into the evolution of reproductive isolation. For example, among the neotropical species of Echinometra, positive selection and rapid change has occurred in bindin on the branch leading to E. lucunter (McCartney and Lessios 2004). Consistent with this burst of bindin evolution, the eggs of $E$. lucunter are gametically incompatible with the sperm of its close relatives $E$. viridis and $E$. vanbrunti (McCartney and Lessios 2002). Similarly, there has been a burst of changes in bindin along the lineage leading to Heliocidaris erythrogramma.
The eggs of $H$. erythrogrammaare gametically incompatible with sperm from H. tuberculata (Zigler et al., 2003).

What explains a history of positive selection on bindin in some, but not all, sea urchin genera? Does a single evolutionary force explain all observed selection on bindin, or might different forces be acting in different genera? Though these questions have been discussed recently, the answers are not clear (Palumbi and Lessios 2005; Lessios 2007). If selection on bindin is occurring due to interactions between species, reinforcement - selection to prevent the formation of unfit hybrids between closely related species - is one possible answer. Positive selection on bindin has only been observed in genera that have sympatrically distributed species (Table 1), which is consistent with the hypothesis that the observed pattern may be the result of reinforcement. Bindin evolution driven by reinforcement would increase interspecific bindin divergence, while minimizing intraspecific bindin divergence, as is observed in H. erythrogramma and E. lucunter (McCartney and Lessios 2004; Zigler et al., 2005).

In addition, Geyer and Palumbi (2003) found reproductive character displacement for bindin alleles between the closely related Indo-Pacific species E. oblonga and E.sp. C. E. oblonga is found in the central and western Pacific, and exhibits four bindin types, that differ by nonsynonymous differences and small insertions, with allelic variation within each type. Two of these bindin types are found in E.sp. C, and two are not. In the central Pacific, where $E$. oblonga is present but $E$. sp. $C$ is not, $E$. oblonga populations exhibit all four bindin types. In the western Pacific, where the species have overlapping ranges, the only E. oblonga bindin types observed are those that are not found in $E$. sp. C. Geyer and Palumbi (2005) have also shown that these allelic differences influence gamete compatibility. This pattern of distinct bindin types present in areas where the two species overlap is consistent with reinforcement between these two species. Thus, in both Heliocidaris and the neotropical Echinometra, reinforcement may explain the observed selection on bindin, and reinforcement may explain the distribution of bindin alleles within the ranges of $E$. oblonga and $E$.sp. C.

\section{Bindin evolution within species}

Reinforcement, however, is not sufficient to explain the observed patterns of bindin diversity within the Indo-Pacific Echinometra and the eastern Pacific Strongylocentrotus. These species display a large amount of allelic diversity and, in the IndoPacific Echinometra species, an excess of nonsynonymous changes to synonymous changes in intraspecific comparisons (Metz and Palumbi 1996; Debenham et al., 2000). In addition, two 
studies have examined the relationship between male bindin genotype and female bindin genotype with remarkable results. The first of these studies examined the Indo-Pacific species $E$. mathaei. E. mathaei has a large amount of intraspecific bindin diversity; on a gene genealogy for bindin from $E$. mathaei, four clades are evident: A, B, C, and D (after Palumbi 1999). These bindin clades differ by short insertions and deletions and nonsynonymous changes. Palumbi (1999) fertilized eggs from females with known bindin genotype with a mixture of sperm from two males: one homozygous for ' $A$ ' type bindin alleles, and one homozygous for ' $B$ ' type bindin alleles. Individual larvae were subsequently genotyped. He found that eggs from ' $A A$ ' females were more likely to be fertilized by sperm from 'AA' males, and that eggs from 'BB' females were more likely to be fertilized by sperm from 'BB' males. Thus, E. mathaeindividuals exhibit assortative mating based on bindin genotype, at least in the particular cross examined.

Levitan and Ferrell (2006) studied male and female reproductive success in induced field spawnings of groups of Strongylocentrotus franciscanus. $\mathcal{S}$. franciscanus is another species with substantial intraspecific bindin diversity; in the population studied here, fifteen alleles were identified. In addition to finding the expected effects relating to distance between individuals, Levitan and Ferrell (2006) uncovered the remarkable pattern that at low densities, individuals that shared their bindin genotype with a high frequency of potential mates had the greatest reproductive success, whereas at high density, the reverse was true. At low densities, this is similar to Palumbi's (1999) result with $E$. mathaei. At high densities, it may be disadvantageous to match bindin genotypes with (and thus fertilize well with) many potential mates due to the danger of polyspermy, which prevents normal development and decreases reproductive success at high sperm concentrations. Thus, an interaction of sperm density with bindin allele frequency is likely to have significant effects on bindin evolution within this species. In a high density population, the persistence and spread of rare bindin alleles will be favored, as females with rare alleles are in less danger of losing eggs to polyspermy. In a low density population, the persistence and spread of rare bindin alleles could be suppressed if females with these alleles have reduced reproductive success. Whether or not this density dependent pattern is present in species other than $\mathcal{S}$. franciscanus is not known.

Why is mating success influenced by the bindin genotype of females at all? Since there is no evidence that bindin is expressed in ovaries (thus ruling out some sort of a bindin-bindin interaction between sperm and egg at fertilization) (Gao et al., 1986), the most likely explanation for the results in Echinometra mathaeiand Strongylocentrotus franciscanus is that linkage disequilibrium exists between bindin and some other locus involved with fertilization. Such a linkage is expected, because offspring of a female with a particular preference for a male trait will inherit both the mother's preference and the father's trait. The most likely candidate for the other half of this possible relationship, the egg receptor for bindin, is discussed below.

\section{Bindin receptor}

Progress towards identifying the egg receptor stalled until Kamei and Glabe (2003) cloned and sequenced the egg receptor for bindin (EBR1) from Strongylocentrotus franciscanus and $\mathcal{S}$. purpuratus. In contrast to bindin, EBR1 is a massive molecule 4595 amino acids in $\mathcal{S}$. franciscanus, 3713 amino acids in $\mathcal{S}$. purpuratus (Kamei and Glabe 2003). EBR1 contains a variety of repeats, and the number and structure of these repeats differs between the two species. EBR 1 has not yet been cloned and sequenced in any other species, and assessing intraspecific variation of such a large molecule is daunting. Doing so, however, should answer the question as to whether linkage disequilibrium between bindin and EBR1 explains the intraspecific fertilization results from Echinometra mathaeiand $S$. franciscanus. Additionally, though the sequencing of the $\mathcal{S}$. purpuratus genome is complete, contigs have not yet been mapped onto chromosomes (as of October 2007). Once this has been done, we will know if there is physical linkage between bindin and EBR1, at least in $S$. purpuratus.

\section{Future directions}

Vacquier et al. (1995) proposed three lines of future research: studying bindin evolution in the neotropical Echinometra, conducting fertilization experiments to determine the effects of intraspecific variation on fertilization success, and solving the crystallographic structure of bindin. The first of these lines of research has been completed, the second has seen promising beginnings, and there has been no progress on the third. McCartney and Lessios (2004) examined bindin evolution in the neotropical Echinometraand identified an episode of positive selection on the E. Iucunterlineage that is correlated with the evolution of gametic incompatibility. Studies by Palumbi (1999) and Levitan and Ferrell (2006) on intraspecific variation have opened the door to potential explanations of how bindin evolves within species. Unfortunately, the crystal structure of bindin has not been solved, which has limited the ability of researchers to interpret their cell biological and evolutionary results.

What are promising questions for researchers to pursue in the future? As suggested by Vacquier et al. (1995), obtaining the crystal structure of bindin would be invaluable. Combining the atomic structure of bindin with amino acid sequences known from more than thirty species would allow for the clearest picture yet of how bindin functions and evolves. Mapping amino acid changes between closely related species onto a crystal structure would clarify how changes in bindin are related to gamete compatibility. Another useful line of research would be to clarify how the complete bindin molecule, not just the $\mathrm{B} 18$ region, interacts with membranes. Research along these lines would support or reject the idea that bindin functions as a membrane fusogen. Finally, further research clarifying how bindin and the egg receptor for bindin interact would be valuable. Sea urchins are one of the few systems where the egg and sperm participants in sperm-egg attachment have been characterized. Research on the interactions of these molecules promises to provide insight into gamete interactions in general.

Studies of bindin evolution of distantly related echinoids would be informative. Though the echinoids are a diverse group, the vast majority of research on bindin evolution has focused on members of a single order (the Echinoida) of sea urchins. Does bindin evolve differently in sand dollars, heart urchins or pencil urchins? At present, we have no idea. One particularly interesting genus for 
study is Moira, a heart urchin. Moira consists of five species that are allopatrically distributed. Bindin has been cloned from Moira clotho, and it contains repeats 5' of its core (Zigler and Lessios 2003a). To date, positive selection on bindin has only been observed in genera that have repeats, and only in genera that are members of the order Echinoida. Studying Moira gives us a chance to separate those two features: is the presence of repeats correlated with positive selection, or is positive selection correlated observed only in the order Echinoida? Studies of bindin in other species of the Spatangoida would also help clarify whether the repeats seen in Moira are specific to this genus, or are a shared feature of all spatangoids.

Last, we need to know if bindin is in linkage disequilibirium with its receptor (or some other egg component), particularly in Echinometra mathaeiand Strongylocentrotus franciscanus, where current evidence suggests such linkage disequilibrium exists (Palumbi 1999; Levitan and Ferrell 2006). Should this be true in these species, it will then be important to determine how broadly this is true; again, the echinoids are a diverse group. If linkage disequilibrium is present, then several questions can be addressed: Does the presence of linkage disequilibrium explain patterns of intraspecific bindin diversity across the echinoids? Does the presence of linkage disequilibrium explain interspecific patterns of bindin evolution, or do other selective forces, such as reinforcement, play a role? Finally, do echinoid groups that exhibit linkage disequilibrium speciate more rapidly than groups that do not?

What have we learned about sea urchin bindin over the past thirteen years? We now have a clearer picture of how bindin functions, how it is distributed taxonomically, how it evolves, and with what it interacts with on the egg surface. Many promising avenues of research are open, and hopefully the next thirteen years will see today's mysteries solved, and new questions raised.

\section{Acknowledgments}

I thank H. Lessios for his comments on this manuscript, as well as for his collaboration and advice on bindin research over the past decade.

\section{References}

AFONIN, S., U.H.N. DURR, R.W. GLASER, and A.S. ULRICH. (2004). 'Boomerang'-like insertion of a fusogenic peptide in a lipid memrane revealed by solidstate ${ }^{19} \mathrm{~F}$ NMR. Magnetic Resonance in Chemistry 42:195-203.

BIERMANN, C. H. (1998). The molecular evolution of sperm bindin in six species of sea urchins (Echinoida:Strongylocentrotidae). Mol. Biol. Evol. 15:1761-1771.

DAN, J.C. (1967). Acrosome reaction and lysins. In Fertilization Vol. 1. (eds. C.B. Metz and A. Monroy) pp. 237-293. New York: Academic Press.

DEBENHAM, P., M.A. BRZEZINSKI, and K.R. FOLTZ. (2000). Evaluation of sequence variation and selection in the bindin locus of the red sea urchin, Strongylocentrotus franciscanus. J. Mol. Evol. 51:481-490.

GAO, B., L.E. KLEIN, R.J. BRITTEN, and E.H. DAVIDSON. (1986). Sequence of mRNA coding for bindin, a species-specific sperm protein required for fertilization. Proc. Nat. Acad. Sci. USA 83: 8634-8638.

GEYER, L.B. and S.R. PALUMBI. (2003). Reproductive character displacement and the genetics of gamete recognition in tropical sea urchins. Evolution 57:1049-1060.

GEYER, L.B. and S.R. PALUMBI. (2005). Conspecific sperm precendence in two species of tropical sea urchins. Evolution 59:97-105.

GLABE, C.G. (1985a). Interaction of the sperm adhesive protein, bindin, with phospholipid vesicles. I. Specific association of bindin with gel-phase vesicles.
J. Cell Biol. 100:794-799.

GLABE, C.G. (1985b). Interaction of the sperm adhesive protein, bindin, with phospholipid vesicles. II. Bindin induces the fusion of mixed-phase vesicles that contain phosphatidylcholine and phosphatidylserine in vitro. J. Cel/ Biol. 100:800806.

GLABE, C.G. and D. CLARK. (1991). The sequence of the Arbacia punctulata bindin cDNA and implications for the structural basis of species-specific sperm adhesion and fertilization. Dev. Biol. 143: 282-288.

GLABE, C.G. and W.J. LENNARZ. (1979). Species-specific sperm adhesion in sea urchins: a quantitative investigation of bindin-mediated egg agglutination. $J$. Cell Biol. 83:595-604.

KAMEI, N. and C.G. GLABE. (2003). The species-specific egg receptor for sea urchin sperm adhesion is EBR1, a novel ADAMTS protein. Genes Dev. 17:25022507.

LESSIOS, H.A. (2007). Reproductive isolation between species of sea urchins. Bull. Mar. Sci. 81:191-208.

LOPEZ, A., S.J. MIRAGLIA, and C.G. GLABE. (1993). Structure/function analysis of the sea urchin sperm adhesive protein bindin. Dev. Biol. 156: 24-33.

MCCARTNEY, M.A. and H.A. LESSIOS. (2002). Quantitative analysis of gametic incompatibility between closely related species of neotropical sea urchins. Biol. Bull. 202:166-181.

MCCARTNEY, M.A. and H.A. LESSIOS. (2004). Adaptive evolution of sperm bindin tracks egg incompatibility in neotropical sea urchins of the genus Echinometra. Mol. Biol. Evol. 21: 732-745

METZ, E. C. and S. R. PALUMBI. (1996). Positive selection and sequence rearrangements generate extensive polymorphism in the gamete recognition protein bindin. Mol. Biol. Evol. 13:397-406.

METZ, E.C., G. GÓMEZ-GUTIÉRREZ, and V.D. VACQUIER. (1998). Mitochondrial DNA and bindin gene sequence evolution among allopatric species of the sea urchin genus Arbacia. Mol. Biol. Evol. 15:185-195.

MINOR, J. E., D. R. FROMSON, R. J. BRITTEN, and E. H. DAVIDSON. (1991). Comparison of the bindin proteins of Strongylocentrotus franciscanus, $\mathcal{S}$. purpuratus, and Lytechinus variegatus: sequences involved in the species specificity of fertilization. Mol. Biol. Evol. 8:781-795.

MOY, G.W. and V.D. VACQUIER. (1979). Immunoperoxidase localization of bindin during the adhesion of sperm to sea urchin eggs. Curr. Top. Dev. Biol. 13:3144.

PALUMBI, S.R. (1999). All males are not created equal: fertility differences depend on gamete recognition polymorphisms in sea urchins. Proc. Nat. Acad. Sci. 96:12632-12637.

PALUMBI, S.R. and H.A. LESSIOS. (2005). Evolutionary animation: How do molecular phylogenies compare to Mayr's reconstruction of speciation patterns in the sea? Proc. Nat. Acad. Sci. USA 102:6566-6572.

SEA URCHIN GENOME SEQUENCING CONSORTIUM. (2006). The genome of the sea urchin Strongylocentrotus purpuratus. Science 314:941-952.

SEIDAH, N.G. and M. CHRETIEN. (1999). Proprotein and prohormone convertases: a family of subtilases generating diverse bioactive polypeptides. Brain Res. 848:45-62.

SMITH, A.B., D. PISANI, J.A. MACKENZIE-DODDS, B. STOKLEY, B.L. WEBSTER, and D.T.J. LITTLEWOOD. (2006). Testing the molecular clock: molecular and paleontological estimates of divergence times in the Echinoidea (Echinodermata). Mol. Biol. Evol. 23:1832-1851.

SUMMERS, R.G., B.L. HYLANDER, L.H. COLWIN, and A.L. COLWIN. (1975). The functional anatomy of the echinoderm spermatozoon and its interaction with the egg at fertilization. Am. Zool. 15:523-551.

SWANSON, W.J. and V.D. VACQUIER. (2002). The rapid evolution of reproductive proteins. Nature Rev. Genetics 3:137-144.

ULRICH, A.S., M. OTTER, C.G. GLABE, and D. HOEKSTRA. (1998). Membrane fusion is induced by a distinct peptide sequence of the sea urchin fertilization protein bindin. J. Biol. Chem. 273:16748-16755.

VACQUIER, V.D. and G.W. MOY. (1977). Isolation of bindin: the protein responsible for adhesion of sperm to sea urchin eggs. Proc. Nat. Acad. Sci. USA 74:2456-2460.

VACQUIER, V.D., W.J. SWANSON, and M.E. HELLBERG. (1995). What have we learned about sea urchin sperm bindin? Develop. Growth Differ. 37:1-10. 
ZIGLER, K.S. and H.A. LESSIOS. (2003a). 250 million years of bindin evolution. Biol. Bull. 205:8-15.

ZIGLER, K.S. and H.A. LESSIOS. (2003b). Evolution of bindin in the pantropical sea urchin Tripneustes: comparisons to bindin of other genera. Mol. Biol. Evol. 20:220-231.

ZIGLER, K.S. and H.A. LESSIOS. (2004). Speciation on the coasts of the new world: phylogeography and the evolution of bindin in the sea urchin genus
Lytechinus. Evolution 58:1225-1241.

ZIGLER, K.S., E.C. RAFF, E. POPODI, R.A. RAFF, and H. A. LESSIOS. (2003) Adaptive evolution of bindin in the genus Heliocidaris is correlated with the shift to direct development. Evolution 57:2293-2302.

ZIGLER, K.S., M. A. MCCARTNEY, D. R. LEVITAN, and H. A. LESSIOS. (2005). Sea urchin bindin divergence predicts gamete compatibility. Evolution59:23992404.

\section{Related, previously published Int. J. Dev. Biol. articles}

See our recent Special Issue Ear Development edited by Fernando Giraldez and Bernd Fritzsch at: http://www.ijdb.ehu.es/web/contents.php?vol=51\&issue=6-7

Expression of an Otx gene in the adult rudiment and the developing central nervous system in the vestibula larva of the sea urchin Holopneustes purpurescens.

Valerie B Morris, Jing-Ting Zhao, Deborah C A Shearman, Maria Byrne and Marianne Frommer

Int. J. Dev. Biol. (2004) 48: 17-22

The color purple: analyzing alkaline phosphatase expression in experimentally manipulated sea urchin embryos in an undergraduate developmental biology course.

Julie Drawbridge

Int. J. Dev. Biol. (2003) 47: 161-164

Physiological and induced apoptosis in sea urchin larvae undergoing metamorphosis.

Maria C Roccheri, Cinzia Tipa, Rosa Bonaventura and Valeria Matranga

Int. J. Dev. Biol. (2002) 46: 801-806

Transcriptional regulation of the gene for epidermal growth factor-like peptides in sea urchin embryos.

K Yamasu, G Suzuki, K Horii and T Suyemitsu

Int. J. Dev. Biol. (2000) 44: 777-784

Homeobox genes and sea urchin development.

M Di Bernardo, D Bellomonte, S Castagnetti, R Melfi, P Oliveri and G Spinelli Int. J. Dev. Biol. (2000) 44: 637-643

Sperm-egg interaction at fertilization: glycans as recognition signals. F Rosati, A Capone, C D Giovampaola, C Brettoni and R Focarelli Int. J. Dev. Biol. (2000) 44: 609-618

From human to sea urchin development: an interview with Giovanni Giudice.

Gabriella Sconzo

Int. J. Dev. Biol. (2000) 44: 567-573

Analysis of polysulfate-binding domains in porcine proacrosin, a putative zona adhesion protein from mammalian spermatozoa. S Jansen, M Quigley, W Reik and R Jones Int. J. Dev. Biol. (1995) 39: 501-510

Egg-jelly signal molecules for triggering the acrosome reaction in starfish spermatozoa.

M Hoshi, T Nishigaki, A Ushiyama, T Okinaga, K Chiba and M Matsumoto Int. J. Dev. Biol. (1994) 38: 167-174

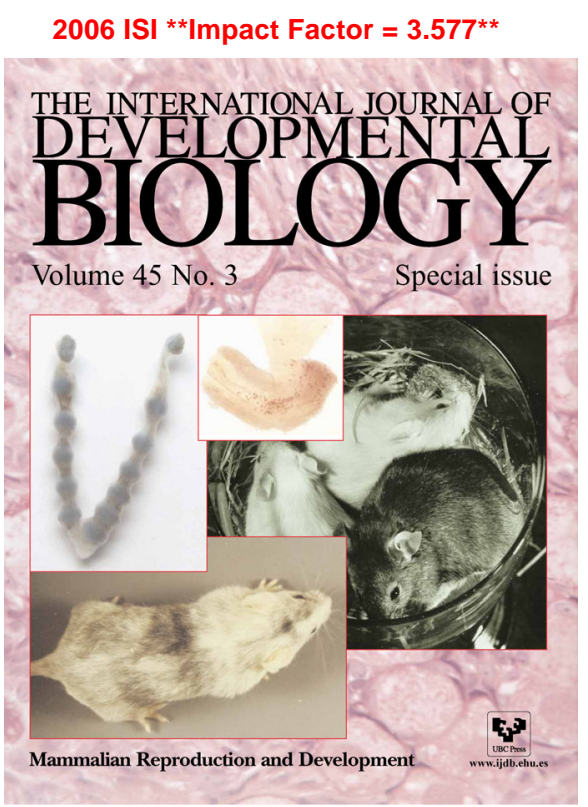

